\title{
A Rotina dos Produtores de TV na Pandemia: A Atuação das Fontes na Coprodução de Conteúdo Jornalístico
}

\author{
Fabiana Siqueira \\ Doutora em Comunicação pela \\ Universidade Federal de Pernambuco, \\ com doutorado sanduíche pela \\ Universidad Complutense de Madrid. \\ Bacharel em Comunicação Social, \\ com habilitação em Jornalismo \\ pela Universidade Federal de Santa \\ Maria (1997) e mestre em Engenharia \\ de Produção com ênfase nas áreas \\ de Qualidade e Produtividade \\ pela Universidade Federal de \\ Santa Maria (2004). \\ E-mail: fabiana.siqueira@academico. \\ ufpb.br
}

\section{Gilmara Dias}

Jornalista, chefe de redação da TV Correio, afiliada da Record TV, na Paraíba. Mestranda em Jornalismo pelo Programa de Pós-Graduação em Jornalismo da Universidade Federal da Paraíba. E-mail: gildias@gmail.com
Resumo: A pandemia da Covid-19 mudou, em diversos aspectos, a vida da humanidade. No campo do jornalismo, foi preciso adequar algumas práticas para preservar a saúde de jornalistas e entrevistados, levando a um aumento na solicitação de vídeos realizados pelo público. Este artigo analisa a consolidação das fontes como produtoras de conteúdo na TV Correio, afiliada da Record TV na Paraíba, e como isso impactou as rotinas produtivas dos produtores dos telejornais no contexto da pandemia. O estudo foi realizado a partir da observação participante feita entre março e setembro de 2020 na emissora e, também, por meio da realização de entrevistas semiestruturadas com os produtores. Entre outras questões, constatou-se que houve uma mudança no papel do produtor, que passou também a orientar as fontes na produção de material audiovisual, criando mecanismos para isso. Essa nova função do produtor deve perdurar nas rotinas produtivas mesmo após o fim da pandemia.

Palavras-chave: telejornalismo, produtores, pandemia, coprodução, TV Correio.

La Rutina de los Productores de TV en la Pandemia: El Papel de las Fuentes en la Coproducción de Contenidos Periodísticos

Resumen: La pandemia del Covid-19 ha cambiado la vida de la humanidad de muchas maneras. En el campo del periodismo, fue necesario adecuar algunas prácticas para preservar la salud de los periodistas y de entrevistados, y, consecuentemente, se incrementó la demanda de videos realizados por el público. Este artículo analiza la consolidación de fuentes como productoras de contenido en TV Correio, afiliada a Record TV, en Paraíba (Brasil), y cómo esto impactó las rutinas productivas de los productores de informativos en el contexto de la pandemia. En este estudio se utilizaron la observación participante, llevada a cabo entre marzo y septiembre de 2020 en la emisora, y entrevistas semiestructuradas con productores. Entre otras cuestiones, hubo un cambio en el rol del productor, quien también comenzó a orientar a las fuentes en la producción de material audiovisual, creando mecanismos para ello. Esta función puede permanecer en rutinas productivas, incluso con el fin de la pandemia.

Palabras clave: periodismo televisivo, productores, pandemia, coproducción, TV Correio.

Routine of TV Producers in the Pandemic: The Role of Sources in the Co-Production of Journalistic Content

Abstract: The COVID-19 pandemic has changed people's lives in many ways. Within journalism, some practices had to be adapted to preserve the health of journalists and interviewees, leading to an increase in the request for videos made by the public. This paper analyzes the consolidation of sources as content producers on TV Correio, a Record TV affiliate in Paraíba, and how this impacted the production routines of newscast producers during the pandemic. Data collection took place between March and September 2020 at the station via participant observation and semi-structured interviews with the producers. Among other issues, we found that there was a change in the producer's, who started to guide sources on the production of audiovisual material, creating mechanisms for this. This new role is expected to remain in production routines even after the pandemic ends.

Keywords: TV journalism, producers, pandemic, co-production, TV Correio. 
Os anos de 2020 e 2021 foram marcados por drásticas mudanças nos mais diversos segmentos em todo o mundo. No jornalismo, a pandemia do coronavírus alterou as formas de trabalho em todas as etapas de produção da notícia. A equipe de reportagem de TV, por exemplo, para evitar transmissão ou contágio tanto dos profissionais quanto dos entrevistados no momento das entrevistas, precisou adotar várias medidas sanitárias como o uso obrigatório de máscaras, higienização intensa de equipamentos, uso de um microfone para o repórter e outro para o entrevistado para que fosse possível manter um distanciamento social adequado (Siqueira \& Monteiro, 2020; Emerim et al., 2020). No entanto, ainda assim, em muitos casos não era possível realizar a entrevista de forma presencial. Foi então que as emissoras de televisão passaram a se valer em maior grau de materiais produzidos pelos próprios especialistas ou personagens das reportagens, como são chamados, no jargão jornalístico, os entrevistados que exemplificam o assunto abordado (Paternostro, 1999).

A estratégia das emissoras de TV de utilizar vídeos produzidos pelo público na construção do produto jornalístico não é algo recente (Vizeu \& Siqueira, 2009), porém, durante a pandemia, os profissionais passaram a ir ainda mais em busca desse conteúdo, ao invés de aguardar pelo envio espontâneo do material, e mudaram também o enfoque, envolvendo diretamente as fontes. Houve um estímulo maior a esse tipo de produção e, em algumas situações, os jornalistas se tornaram tutores das fontes que tinham menos intimidade com os recursos tecnológicos, pois existia a necessidade de se obter vídeos gravados pelos próprios entrevistados para a elaboração de reportagens.

Entendemos o conceito de fonte na perspectiva de Schmitz (2011, p. 9), que argumenta que:

Fontes de notícias são pessoas, organizações, grupos sociais ou referências; envolvidas direta ou indiretamente a fatos e eventos; que agem de forma proativa, ativa, passiva ou reativa; sendo confiáveis, fidedignas ou duvidosas; de quem os jornalistas obtêm informações de modo explícito ou confidencial para transmitir ao público, por meio de uma mídia.

Neste caso, a abordagem parte da atuação mais ativa da fonte e o trabalho do jornalista passa a ser no sentido de obter conteúdo em vídeo captado pela própria fonte. Esse material é essencial, tendo em vista que a imagem é a matéria-prima da televisão (Paternostro, 1999) e a gravação de entrevistas, um elemento importante do processo de construção das reportagens. As sonoras, como são chamadas as entrevistas dentro das reportagens ou em outros formatos do telejornalismo, humanizam e auxiliam na contextualização das informações, trazem explicações, vivências, relatos etc.

Na redação, esse papel "professoral" que o jornalista exerce ao se tornar tutor da fonte que não tem afinidade com a tecnologia de gravação de vídeos para o telejornalismo cabe geralmente ao produtor, pois é quem desempenha o processo inicial de construção da notícia, além de ser o responsável por checar informações e elaborar a pauta, dando suporte aos repórteres e editores (Barbeiro \& Lima, 2005). Dentro desse cenário, cada vez mais, o jornalista precisa dedicar parte do tempo da rotina de trabalho a orientar o público sobre como produzir os vídeos que serão utilizados.

Neste trabalho, buscamos analisar a consolidação das fontes como produtoras de conteúdo em uma emissora de TV em particular, a TV Correio, afiliada da Record TV em João Pessoa, na Paraíba, e como isso impactou as rotinas produtivas dos produtores dos telejornais dessa empresa de comunicação no contexto da pandemia.

Antes da Covid-19, a TV Correio já utilizava sonoras e imagens gravadas pelo público em um quadro específico, que será abordado mais adiante. Porém, o uso desse material nas pautas diárias, na captação de sonoras dos entrevistados, era uma prática muito rara.

O estudo é de caráter exploratório e foi realizado a partir da observação participante (Wolf, 1999) e da realização de entrevistas semiestruturadas (Duarte, 2005) com os produtores da emissora. Antes de detalhar outros aspectos da metodologia, é importante destacar alguns conceitos que contribuíram para o embasamento deste trabalho. 


\section{A redação e as rotinas produtivas}

Independentemente do veículo de comunicação, as rotinas no trabalho da produção de notícias seguem, de modo geral, um padrão básico. Dentro dessa rotina produtiva, Wolf $(1999$, p. 218) elenca três importantes etapas que são "a recolha, a seleção e a apresentação. Cada uma delas dá lugar a rotinas articuladas e a processos de trabalho, dos quais só alguns aspectos são tratados".

A solicitação de vídeos e a captação do material envolvem as fases de recolha e seleção do conteúdo jornalístico, uma vez que estão situadas nas etapas de planejamento e execução, que são essenciais para a construção da notícia. A participação do público de forma direta ou indireta envolve um processo de abertura, que vem se ampliando de diferentes formas, ao longo da história do telejornalismo.

Não é de hoje que fontes (Schmitz, 2011) e o público em geral (coprodutores) fazem registros audiovisuais que acabam sendo utilizados na televisão, como afirmam Zanotti (2010) e Vizeu e Siqueira (2009), mas é evidente que, no momento atual, há uma oferta maior desse tipo de material, provocada tanto pelas facilidades de captação (por meio de dispositivos móveis, como o celular) quanto pelas possibilidades rápidas de difusão (mediante redes sociais e aplicativos conectados à internet).

Vaz (2013) reforça, inclusive, que é uma tendência que tem sido muito usada pelas grandes empresas de comunicação. Nelas, o público tem a oportunidade de produzir conteúdo dentro dos padrões do telejornal. De acordo com Siqueira (2013, p. 57), "se antes as pessoas chamavam os jornalistas para registrar determinadas situações e denúncias, agora, elas já oferecem a informação visual ou audiovisual. Querem a divulgação legitimada do que testemunharam".

A tecnologia é um elemento primordial nesse processo. Para Silva (2018, p. 19), "o jornalismo televisivo tem sido desafiado a rever suas rotinas produtivas e adaptar seus conteúdos a múltiplas telas e múltiplos públicos. Televisão e tecnologia caminham juntas quando se trata de formato e conteúdo". Nesse contexto, os papéis tanto dos jornalistas quanto da audiência ativa (Pereira \& Alves, 2017) e das fontes ganham novas roupagens. O profissional deixa de ser o grande protagonista, como afirma Fausto Neto (2011, p. 26):

Instituições e atores sociais tomam parte desta "arquitetura" não mais como agentes, mas, através de novos papéis segundo novos protagonismos de interação. Passam a ser atores a quem são acenadas possibilidades crescentes de manejo de operações tecno-midiáticas com as quais passam a codificar a realidade e instituir novas narratividades.

Carvalho e Lage (2012, p. 246) reforçam que "diante da tecnologização dos processos sociais e das formas de interação, ambos corolários da midiatização, podemos assumir que a própria mídia, enquanto instância social ordenadora de processos interacionais, também se vê afetada pela nova ordem comunicacional". Percebendo esse crescente e intenso acesso da população à internet e a celulares que permitem a produção de imagens com qualidade aceitável para exibição na televisão, os veículos passaram a usar isso em favor próprio. No período pós-industrial, dentro da comunicação, essa participação ganhou diversas nomenclaturas como jornalismo cidadão (Targino, 2009), colaborativo (Zanotti, 2010) ou participativo (Holanda et al., 2008). No entanto, também se defende que tal ação por parte da população não deveria ser enquadrada como jornalismo.

Esses cidadãos e cidadãs não jornalistas passam a ocupar um novo espaço no processo de produção da notícia como coprodutores da mesma, o que lança novos desafios ao Jornalismo. $O$ repórter-cidadão, na falta de um conceito mais consistente, é um coprodutor da notícia e o jornalista neste processo permanece como o produtor da informação. (Vizeu et al., 2010, p. 9)

Para Baccega (1998, p. 390) "os receptores tornam-se coprodutores do produto cultural. São eles que o (re)vestem de significado, possibilitando a atualização de leituras, o rompimento de caminhos pré-estabelecidos de significados, a abertura de trilhas que poderão desaguar em reformulações culturais". 
${ }^{1}$ https://globoplay.globo.com/v/7054932/.

Siqueira (2013, p. 20) entende os coprodutores como "pessoas de várias profissões - donas de casa, professores, engenheiros, pedreiros, policiais, cozinheiros etc-, que no dia a dia exercem outras funções, no entanto, eventualmente, captam imagens selecionadas e utilizadas nos programas jornalísticos de televisão".

Ao perceber que lhes estava sendo dado esse espaço nos veículos de comunicação, o público passou a fazer, em maior quantidade, esses registros cotidianos e a enviá-los aos jornalistas. Os veículos rapidamente também perceberam as benesses que essa produção traria e passaram a estimular o telespectador, como afirmam Carvalho e Lage (2012, p. 253):

Como parte de uma estratégia de aproximação, leitores, ouvintes e espectadores são cada vez mais chamados a colaborar, a participar do processo de produção das notícias. Assim, são postos na condição de coprodutores. Investidos no papel do "eu repórter", esses agentes não apenas denunciam, como também produzem e reproduzem o próprio material jornalístico (fotos, vídeos, notícias...), direta ou indiretamente, corrigem e atualizam informações, reafirmando e ressaltando sua importância nos processos de mediação implicados nas operações jornalísticas - modificando, assim, a própria prática jornalística enquanto mediação social.

Um exemplo dessa participação que já existia no telejornalismo antes da pandemia é o quadro "O Brasil que eu quero", criado pelo Grupo Globo por conta das eleições de 2018. Foram recebidos 50 mil vídeos de todo o país, ao longo de sete meses de existência do projeto e o conteúdo, enviado pelo público por meio do portal de notícias G1, foi exibido nos telejornais da TV Globo ${ }^{1}$.

Em João Pessoa, na Paraíba, a TV Correio, afiliada da Record TV, também apresenta, desde 2018, um quadro chamado "Sou Repórter Correio" (Siqueira, 2018).

${ }^{2}$ WhatsApp é um aplicativo de troca de mensagens instantâneas que pode ser instalado em celulares e computadores e permite também chamadas de áudio e de vídeo, assim como o envio de arquivos, fotos e vídeos.

${ }^{3}$ A solicitação para que o material seja gravado com o celular na posição horizontal é para que as imagens se adequem melhor ao formato dos televisores. No entanto, acompanhando a programação, é fácil perceber que muitos vídeos enviados ainda são gravados na posição vertical, como é comum nas redes sociais.
Nele, os telespectadores, por meio de um número de WhatsApp", são incentivados a produzir vídeos tanto para os telejornais quanto para as chamadas que são exibidas ao longo da programação nos intervalos comerciais. $O$ conteúdo se refere a algum tipo de problema em determinada comunidade, alguma situação de flagrante, denúncias, bem como alguma ação positiva que o cidadão gostaria de mostrar. Nesta "convocação", explica-se como o vídeo deve ser produzido. O telespectador é orientado a dizer o nome, de onde fala e fazer o relato desejado, tudo isso gravado com o celular na posição horizontal ${ }^{3}$. O material que chega até a emissora é exibido em todos os programas jornalísticos.

Com a pandemia, houve um aumento na exibição, durante os telejornais, de vídeos que não foram captados pelas equipes das emissoras de televisão. Algo que já era estimulado entre os coprodutores passou a ser utilizado, em larga escala, também com as fontes.

Por conta da Covid-19, as entrevistas feitas com as fontes deixaram, em muitos casos, de ser feitas presencialmente pela necessidade das próprias emissoras de proteger os profissionais e os entrevistados por meio da redução da quantidade de pessoas circulando nas redações e nas ruas, entre outros fatores. Neste trabalho, optamos por analisar como essa participação durante a pandemia impactou as rotinas produtivas dos produtores de telejornais e como a fonte se consolidou como produtora de conteúdo em vídeo. Para isso, optamos por realizar o estudo na TV Correio, com olhar voltado para o trabalho diário dos produtores durante a pandemia, sem levar em consideração o quadro "Sou Repórter Correio", que envolve outro tipo de público, os coprodutores.

Para compreender de fato essas mudanças e o estreitamento da relação dos produtores com as fontes, escolhemos como método a observação participante (Wolf, 1999), acompanhando as rotinas produtivas da emissora de março a setembro de 2020.

A observação participante é um instrumento de coleta que pode ser utilizado em pesquisas de caráter etnográfico, em que há uma imersão dos pesquisadores no ambiente estudado. 
A etnografia faz parte do trabalho de campo do pesquisador. E é entendida como um método de pesquisa qualitativa e empírica que apresenta características específicas. Ela exige um "mergulho" do pesquisador, ou seja, não é um tipo de pesquisa que pode ser realizada em um período muito curto e sem preparo. (Travancas, 2005, p. 100)

O acompanhamento foi realizado diariamente, de segunda à sexta, ao longo de sete meses, indo, geralmente, das 11 às 20 horas. Isso foi possível, pois uma das autoras deste estudo trabalha na referida empresa de comunicação como jornalista. Essa abordagem permitiu que se analisasse o trabalho dos produtores mais de perto e se produzissem apontamentos a partir dos seguintes eixos: a relação entre os produtores e as fontes, os procedimentos para solicitação de imagens das fontes e as formas de recebimento e encaminhamento das cenas.

Com a finalidade de complementar as informações, escolhemos ainda ouvir relatos de pessoas diretamente envolvidas no processo de construção da notícia, realizando entrevistas semiestruturadas com dois produtores da TV Correio que aqui são identificados como Produtor 1 e Produtor 2.

A entrevista semiestruturada, também chamada de entrevista semiaberta (Duarte, 2005) é realizada a partir de um roteiro.

O roteiro exige poucas questões, mas suficientemente amplas para serem discutidas em profundidade sem que haja interferências entre elas ou redundâncias. A entrevista é conduzida, em grande medida, pelo entrevistado, valorizando seu conhecimento, mas ajustada ao roteiro do pesquisador. A lista de questões-chaves pode ser adaptada e alterada no decorrer das entrevistas. (Duarte, 2005, p. 66)

As perguntas foram direcionadas para as rotinas dos produtores, a relação com as fontes, as mudanças nessas relações ocasionadas pela pandemia, os impactos dessas transformações nas rotinas e as perspectivas futuras, levando em consideração o cenário atual.

É importante destacar que, neste artigo, os aspectos constatados ao longo da observação participante foram condensados, pontuados e complementados pelas falas dos produtores durante a análise, tendo em vista que as entrevistas foram realizadas na redação, durante o mesmo período, permitindo questionar sobre situações constatadas na observação do ambiente de trabalho.

O Produtor 1 trabalha diretamente com o programa de política da emissora, o Correio Debate (exibido à tarde), no entanto, caso seja necessário, também dá suporte ao Jornal da Correio (telejornal do período noturno). Ele auxilia tanto na elaboração de alguma pauta quanto no apoio aos repórteres quando estes estão na rua fazendo a reportagem e necessitam de algum tipo de ajuda. O Produtor 2 trabalha especificamente para o Jornal Correio.

\section{Produção da TV Correio e a relação com as fontes}

A interação entre emissoras de televisão e o público não é algo novo e tem mudado ao longo dos anos. Mais que ter um contato com o veículo, o cidadão passou a dominar técnicas de produção de conteúdo audiovisual e vários canais de acesso às redações foram sendo criados. De acordo com Fausto Neto (2011, p. 21):

A midiatização corresponde ao desenvolvimento de processos crescentes e complexos de tecnologias, convertidas em meios e em operações tecno-discursivas, através de processos de produção e de recepção de discursos que afetam a sociedade, no âmbito de práticas das instituições e a dos atores sociais, gerando novas e complexas formas de contatos e de interações.

Cerqueira $(2018$, p. 99) diz que "o uso das tecnologias pela audiência na construção dos fatos telejornalísticos traz novas significações, redesenha o papel do cidadão consumidor potencial produtor de conteúdo que integra, interinamente ou parcialmente, os produtos jornalísticos". Esse domínio da tecnologia também 
${ }^{4}$ Forma como são chamadas as entrevistas captadas para as reportagens no telejornalismo.

\footnotetext{
${ }^{5}$ Como são chamadas as imagens complementares, que servem para agregar informação visual à reportagem e que facilitam o processo de edição.
}

atinge as fontes, que passaram a produzir vídeos em maior quantidade a partir do estímulo dos jornalistas.

Durante a pandemia de Covid-19, a participação do público na TV Correio foi além da demanda espontânea e dos envios solicitados para o quadro "Sou Repórter Correio". Em janeiro de 2020, a programação da emissora contava com sete programas diários. Para cumprir com essa produção local, dispunha de uma equipe formada por dez editores de texto, sendo três deles editores adjuntos, além de seis produtores e um jovem aprendiz.

Na observação participante, constatamos que a rotina produtiva de toda a emissora sofreu vários impactos e isso se refletiu no trabalho dos produtores e demais profissionais. A empresa distribuiu os profissionais, que antes ficavam todos em uma mesma redação, em salas separadas para que houvesse distanciamento social, tentando minimizar os riscos de contágio dentro do ambiente de trabalho.

Outras mudanças nas rotinas também ocorreram. Até então, os repórteres costumavam chegar à redação e recebiam dos produtores as pautas do dia. Uma pauta (Paternostro, 1999) é composta por alguns elementos básicos como a proposta, ou seja, o que se quer de fato da reportagem, o encaminhamento uma espécie de roteiro com indicações das etapas através das quais a reportagem vai ser construída - e as informações para que o repórter tenha subsídios na hora de construir os textos, além dos dados de contato das fontes. Nela, também são indicadas as pessoas que serão entrevistadas naquela reportagem.

Com a pauta na mão, o repórter se junta ao cinegrafista e a equipe vai para as ruas para cumprir o que foi programado. Por causa da Covid-19, de acordo com o Produtor 1 , muitos entrevistados passaram a ter receio de receber a equipe de reportagem, como foi identificado na observação participante e relatado pelos produtores:

nas vezes que era necessário "pegar" sonora4 com alguém presencialmente, a gente sentia uma grande resistência por parte das pessoas. Mesmo a marcação sendo em um lugar aberto, usando dois microfones, havia resistência. (Produtor 1, comunicação pessoal)

Devido à necessidade de se manter o distanciamento social por questão de segurança tanto dos entrevistados quanto das equipes, a forma encontrada pelos jornalistas para que as reportagens pudessem ser feitas da melhor forma possível, ouvindo personagens e especialistas, foi por meio de vídeos produzidos pelos próprios entrevistados. De acordo com o Produtor 1, essa foi uma das grandes mudanças na rotina.

A gente precisou, além de pensar nas pautas e de fazer um roteiro para o repórter que já tem um traquejo de como as coisas funcionam, a gente precisou também começar roteirizar para o personagem, ou os personagens quando era o caso, um roteiro mais minucioso, mais detalhado para que eles enviassem o vídeo, não só com depoimento deles, mas também com imagem de apoio ${ }^{5}$, com orientação de cenário bacana para aquilo que o VT quer abordar. Então, isso também exige mais tempo, que é uma coisa que costumeiramente já falta na produção diária de jornal. (Produtor 1, comunicação pessoal)

Para os repórteres, o roteiro citado pelo Produtor 1 era feito na própria pauta e dependia do assunto que seria abordado. Cada temática, cada ambiente demanda uma orientação particular. Já para os personagens, a "roteirização" era feita, primeiramente, verbalmente quando o contato telefônico era realizado para marcar a pauta. Na observação participante foi possível identificar que, além de convencer o entrevistado a falar sobre o tema, era necessário passar orientações quanto à produção do vídeo.

A solicitação de imagens das fontes era realizada, primeiro, por ligação telefônica. Depois de explicar a ideia da pauta, o produtor detalhava para o entrevistado o que gostaria que tivesse nos vídeos produzidos por ele. Sempre eram informadas as perguntas necessárias para a construção da reportagem e quais eram as imagens de apoio necessárias para a edição do material. 
O uso do WhatsApp foi um grande facilitador desse processo. Depois de receber o conteúdo pelo aplicativo, o produtor encaminhava o material para o departamento chamado "geração", também por WhatsApp, e esse setor era responsável por enviar o material para a ilha de edição. Os editores de texto e de imagem eram comunicados da chegada desse conteúdo.

Com a utilização de mais vídeos produzidos pelas próprias fontes foi possível, inclusive, obter conteúdo feito no interior da Paraíba, como no município de Patos, por exemplo, como foi notado durante a observação participante. Apesar de a emissora não contar com uma equipe de reportagem no sertão, desde que esse novo formato foi adotado os produtores passaram a solicitar às fontes que eles produzissem e enviassem vídeos, de qualquer lugar em que estivessem, para compor as reportagens.

Dessa forma, aumentou-se a quantidade de reportagens que passaram a ser construídas completamente na redação, sem que as equipes saíssem da emissora para gravar com alguém. Os vídeos produzidos pelos entrevistados eram enviados pelo celular, o que sempre acarreta perda de qualidade, pois há uma redução na resolução da imagem. Mas esse problema, de acordo com o Produtor 1, ficou em segundo plano:

Houve uma perda de qualidade não só na imagem, mas também na qualidade do som e consequentemente na qualidade daquilo que a gente vai exibir. No entanto, a qualidade deixou de ser prioridade. Eu acho que a informação, nesse cenário aí vai ser a prioridade. A prioridade passou a ser mais ainda informar do que pensar naquele produto trabalhado esteticamente perfeito que a TV sempre pregou. (Produtor 1, comunicação pessoal)

Durante o período de observação participante, de maneira geral percebemos poucas dificuldades na relação entre produtores e fontes. Logo no início da pandemia, algumas pessoas ainda não estavam familiarizadas com as formas de produção de vídeo. Os enquadramentos, a iluminação e os cenários apresentavam algum tipo de problema. Em outros casos, como constatamos, alguma pergunta importante que havia sido passada pelo produtor para a fonte não era gravada, o que fazia com que o profissional precisasse fazer novo contato e nova solicitação. Também presenciamos casos de fontes que se comprometeram em gravar os vídeos solicitados e não enviaram o material, fazendo com que os produtores precisassem demandar mais tempo em busca de um novo entrevistado. Com o passar do tempo, essas rotinas também passaram a ser mais comuns para as fontes e os problemas diminuíram de forma significativa.

O que se observou na pandemia é fruto de um processo contínuo de transformações pelas quais o jornalismo vem passando. Segundo Fausto Neto $(2011$, p. 1), o "jornalismo se vê diante de outra realidade constituída por complexos de 'feixes de relações', que se estabelecem a partir de novos processos técnicos discursivos que se espraiam pelo tecido social, como um todo".

Para o Produtor 2, a pandemia foi um "catalisador de mudanças" e acelerou processos que ainda poderiam levar alguns anos para chegar às redações:

As entrevistas agora, principalmente no setor de política, quase que prioritariamente, a gente tem que fazer pela internet. $O$ personagem, o entrevistado, tem um papel de protagonista na produção também da reportagem. Em certos momentos, eles mesmos produzem o vídeo e eles mesmos ajudam até com imagens de apoio, vão recebendo as nossas orientações. (Produtor 2, comunicação pessoal)

Ainda segundo o Produtor 2, todas as mudanças na forma de fazer entrevistas não foram desafios apenas para entrevistados que, em muitos casos, não tinham muita habilidade com a produção desse tipo de material audiovisual. Os próprios profissionais nas emissoras precisaram encontrar as melhores formas de obter as entrevistas: "foi uma das mudanças que a gente mais sentiu, de primeiro impacto, porque a gente teve que entender como conversar com esse entrevistado, como criar imagens de apoio dessa entrevista" (Produtor 2, comunicação pessoal).

Perguntados sobre o que acreditam que deve se tornar prática comum mesmo depois que a pandemia passar e que as pessoas possam se reaproximar sem 
restrições por causa do risco de contágio pela Covid-19, tanto o Produtor 1 quanto o Produtor 2 concordam que a utilização de vídeos produzidos e enviados pelos próprios entrevistados será algo naturalmente incorporado às rotinas produtivas dos telejornais.

Com toda certeza acredito que o uso de celular para chamadas de vídeo ao vivo e também para que os entrevistados mandem o material que solicitamos vai ser o grande legado da pandemia. Obviamente, não vai ser um recurso usado de maneira tão massiva como está sendo usado agora, mas acho que a TV quebrou aquele molde perfeito e viu que o celular pode ser um grande aliado. (Produtor 1 , comunicação pessoal)

O Produtor 2 acredita que o próprio público vai encarar com mais naturalidade essa forma de produção de reportagem como vem sendo feita:

Todas as mudanças e desafios impostos aos jornalistas alteraram durante a pandemia, além das rotinas produtivas, o papel de cada um dentro da produção da notícia. A matéria-prima de uma reportagem para televisão, isto é, a imagem, antes feita por um cinegrafista profissional, que detém conhecimentos técnicos para captura de um material de qualidade, precisou dividir ainda mais espaço com imagens vindas de fora, produzidas por pessoas que não estão ligadas ao quadro funcional das empresas de comunicação. Logo, um olhar mais atento a esse material teve que ser adotado para que nenhuma imagem indesejada fosse exibida. Isso porque quanto maior for o processo de descentralização da captação de vídeos, maior será o risco de veiculação de conteúdos falsos ou distorcidos. Isso tem exigido, durante a pandemia, mais atenção e mais trabalho da parte dos jornalistas na seleção desses materiais. Na TV Correio, em relação ao conteúdo solicitado às fontes pelos produtores na elaboração das pautas das reportagens, identificamos durante a observação participante que há facilidades no andamento do trabalho e na análise do material, pois os vídeos são fruto de um envio não espontâneo, estimulado e supervisionado de perto pelos próprios jornalistas, o que reduz os riscos de haver distorções e informações falsas.

Os programas não serão mais os mesmos. Eu acho que o modo de se apresentar a notícia já está mudando com a pandemia e o início do novo normal, o telespectador vai compreender. $\mathrm{O}$ antigo produto não vai mais satisfazer esse telespectador pós-pandêmico que está acostumado a ter muito mais, que está cada vez mais consumindo internet. Acho que se o programa não tiver uma conexão real com a internet, com o digital, ele fica para trás. Eu acho que a tecnologia chegou, catalisou com a pandemia e vai emergir cada vez nos programas. (Produtor 2, comunicação pessoal)

\section{Considerações finais}

Por causa da pandemia de Covid-19, o jornalismo precisou olhar para si e encontrar saídas para seguir cumprindo seu principal papel: informar. As redações também passaram por mudanças e, as rotinas produtivas precisaram ser ajustadas para que todos os protocolos sanitários fossem seguidos e, com isso, profissionais e entrevistados tivessem a saúde preservada (Siqueira \& Monteiro, 2020).

Foram justamente as fontes das reportagens que ganharam destaque nesse processo de construção da notícia. A participação do cidadão por meio de materiais audiovisuais produzidos por eles mesmos, já bastante comum nos telejornais, foi bem além do envio espontâneo. Para cumprir o distanciamento social, os produtores passaram a solicitar que o especialista ou personagem gravasse o vídeo que iria compor a reportagem. $\mathrm{O}$ que à primeira vista pode parecer algo simples demandou uma grande mudança nas rotinas produtivas na redação da TV Correio. Além de solicitar, em muitos casos, os profissionais precisaram também orientar o entrevistado sobre a melhor forma de produzir aquele vídeo, já que, para muitos, não é algo com que eles estivessem familiarizados. Foi necessário explicar sobre enquadramento, posição de celular, e reforçar a necessidade de o ambiente ter luz e som adequados. 
Também devido à limitação de proximidade física entre entrevistados e repórteres, muitos dos materiais exibidos nos telejornais passaram a ser inteiramente produzidos sem que as equipes de reportagem sequer saíssem da emissora. As chamadas "matérias de redação", que não são novidade, mas raramente eram produzidas antes da pandemia, passaram a ser exibidas quase diariamente na TV Correio.

Percebemos que a produção da emissora passou a utilizar os vídeos gravados pelas fontes não como um diferencial ou um novo formato. Esse material se tornou essencial para que a reportagem pudesse ser exibida. A qualidade de imagem e som, tão importantes para a televisão, ficaram em segundo plano, abrindo espaço para a informação como algo mais relevante.

Os impactos nas rotinas produtivas dos produtores foram mais sentidos na fase inicial da pandemia, de adaptação à nova situação, durante a descoberta de um caminho para seguir com a reportagem jornalística em tempos de distanciamento social. Aos poucos isso foi sendo incorporado como uma nova realidade dentro da atividade dos produtores, sendo naturalizado na rotina.

Nesse cenário, as fontes, de fato, se consolidaram como produtoras de conteúdo e, pelo olhar dos produtores da TV Correio, é algo que deverá permanecer mesmo após o fim da pandemia da Covid-19, porém com menos intensidade. Isso veio, de certa forma, para facilitar a logística de produção, já que para as fontes é cada vez mais fácil gravar mesmo estando em local distante. Basta ter um celular e internet e o conteúdo poderá ser solicitado, captado e enviado (ao vivo ou gravado) às emissoras de televisão.

\section{Referências}

Baccega, M. A. (1998). Recepção: Nova perspectiva nos estudos de comunicação. Comunicação \& Educação, 12, 7-16. https://doi.org/10.11606/issn.2316-9125.v0i12p7-16

Barbeiro, H., \& Lima, P. R. (2005). Manual de telejornalismo: Os segredos da notícia na TV. Elsevier.

Carvalho, C. A., \& Lage, L. (2012). Midiatização e reflexividade das mediações jornalísticas. In M. A. Mattos, J. Janotti Junior, \& N. Jacks (Orgs.), Mediação \& midiatização (pp. 245-270). EDUFBA; Compós.

Cerqueira, L. (2018). A função pedagógica no telejornalismo: E os saberes de Paulo Freire na prática jornalística. Insular.

Duarte, J. (2005). Entrevista em profundidade. In J. Duarte \& A. Barros (Orgs.), Métodos e técnicas de pesquisa em comunicação (pp. 62-75). Atlas.

Emerim, C., Pereira, A., \& Coutinho, I. (2020). A (re)invenção do telejornalismo em tempos de pandemia. Insular.

Fausto Neto, A. (2011). Transformação do jornalismo na sociedade em vias de midiatização. In A. Fausto Neto, \& J. D. C. Fernandes (Orgs.), Interfaces jornalísticas: Ambientes, tecnologias e linguagens (pp. 17-34). Editora da UFPB.

Holanda, A., Quadros, C., Silva. J. A. B., \& Palacios, M. (2008). Metodologias de pesquisa em jornalismo participativo no Brasil. Brazilian Journalism Research, 4(2), 57-76. https://doi.org/10.25200/BJR.v4n2.2008.164

Paternostro, V. Í. (1999). O texto na TV: Manual de telejornalismo. Campus.

Pereira, A. V., Jr., \& Alves, K. C. (2017). Os espaços de colaboração da audiência ativa no telejornalismo. Intexto, 39, 42-59. https://doi.org/10.19132/1807-8583201739.42-59 
Schmitz, A. A. (2011). Fontes de notícias: Ações e estratégias das fontes no jornalismo. Combook.

Silva, E. M. (2018). Fases do Jornalismo: Uma proposta epistemológica. In C. Emerim, I. Coutinho \& C. Finger (Orgs.), Epistemologias do telejornalismo brasileiro (pp. 19-36). Insular.

Siqueira, F. C. (2013). O efeito de participação do real representado e o surgimento de um novo valor-notícia: o flagrante único de coprodução no telejornalismo (Tese de Doutorado, Universidade Federal de Pernambuco). Repositório Digital da UFPE. https://repositorio.ufpe.br/handle/123456789/10895

Siqueira, F. C. (2018). Estratégias de aproximação com o público na TV: O uso de conteúdo do WhatsApp no "Sou Repórter Correio" [Trabalho apresentado]. 16을 Encontro Nacional de Pesquisadores em Jornalismo, São Paulo, SP, Brasil. http://sbpjor.org.br/congresso/index.php/sbpjor/sbpjor2018/paper/viewFile/1681/774

Siqueira, F. C., \& Monteiro, P. (2020). Jornalismo em tempos de pandemia: Reconfigurações na TV e na Internet. Editora da UFPB.

Targino, M. G. (2009). Jornalismo cidadão: Informa ou deforma? Ibict; UNESCO.

Travancas, I. (2005). Fazendo etnografia no mundo da comunicação. In J. Duarte \& A. Barros (Orgs.), Métodos e técnicas de pesquisa em comunicação (pp. 98-109). Atlas.

Vaz, A. L. (2013). Jornalismo na correnteza: Senso comum e autonomia na prática jornalística. Senac Nacional.

Vizeu, A., \& Siqueira, F. C. (2009). O telejornalismo: O lugar de referência e a revolução das fontes [Trabalho apresentado]. 7o Encontro Nacional de Pesquisadores em Jornalismo, São Paulo, SP, Brasil.

Vizeu, A., Rocha, H., \& Mesquita, G. O. (2010). Cidadão como coprodutor da notícia: Novos desafios ao jornalismo [Trabalho apresentado]. XXXIII Congresso Brasileiro de Ciências da Comunicação, Caxias do Sul, RS, Brasil.

Wolf, M. (1999). Teorias da comunicação. Editorial Presença.

Zanotti, C. A. (2010). Jornalismo colaborativo, gêneros jornalísticos e critérios de noticiabilidade. Revista Comunicação Midiática, 5(1), 28-41. 